\title{
Tenho um problema: não gosto de ler! A jor- nada formativa de uma mediadora de leitura
}

\author{
Flavia Zuberman \\ Ministério de Educação | Argentina \\ Marly Amarilha \\ Universidade Federal do Rio Grande do Norte | Brasil
}

\section{Resumo}

artigo focaliza aspectos de um trabalho etnometodológico que teve como lócus uma escola pública estadual, de ensino fundamental, em Natal - RN (Brasil). Investigou a recepção da leitura de literatura por parte de uma professora de $4^{\circ}$ ano, que revelou não gostar de ler nem se considerar leitora de literatura. Os fundamentos teóricos baseiam-se, principalmente, em Coulon (1995; 1995a), Vigotsky (1989; 1991; 2003), Graves e Graves (1995), Smith (1991), Jauss (2002), Iser (1996; 1999) e Amarilha (2012; 2013 ). Com escuta sensível, procurou-se fornecer andaime à professora em 30 sessões de leitura. Os procedimentos do trabalho foram aplicados com flexibilidade, objetivando atender ao processo formativo. Foram instrumentos duas entrevistas semiestruturadas com a professora, no início e no fim da pesquisa e,

14 um diário de campo. Ressalta-se que, na leitura, a relação texto-vida foi estabelecida pela professora ainda com certa ingenuidade, o que a impediu de vivenciar o ficcional como uma atividade simbólica, lúdica. Entretanto, houve mudanças e a mediação foi fundamental nesse percurso.

Palavras-chave: Leitura de literatura. Mediação. Formação docente.

\section{Tengo un problema: ¡No me gusta leer!: El trabajo formativo de una mediadora de lectura}

\section{Resumen}

El artículo se centra en aspectos de investigación cualitativa y etnometodológica que tuvo como locus una escuela primaria estatal, ubicada en Natal - RN (Brasil). Há investigado La recepción dela lectura de literatura por parte de una maestra de $4^{\circ}$ año a la que, según reveló, no Le gustaba leer y no se consideraba lectora de literatura. Los fundamentos teóricos se basan, principalmente, en Coulon (1995, 1995a), Vigotsky (1989; 1991; 2003), Graves y Graves (1995), Smith (1 991), Jauss (2002), Iser (1996; 1999) y Amarilha (2012; 2013). Con escucha sensible, se procuró proporcionar andamio a la profesora en 30 sesiones de lectura. Los procedimientos de 
investigación fueron aplicados con flexibilidad, tomando encuenta el proceso formativo. Fueron instrumentos dos entrevistas semi-estructuradas, realizadas con la maestra al principio y al final de la investigación y un diario de investigación. Vale destacar que la relación texto-vida fue establecida por la maestra concierta ingenuidad, lo que le impidió vivenciar lo ficcional como una actividad simbólica, lúdica. Sin embargo, hubo cambios y La mediación fue fundamental en este recorrido.

Palabras clave: Lecturade literatura. Mediación. Formación docente.

\section{I have a problem: I don't like to read! A reading mediator formative journey}

\section{Abstract}

The article focus on aspects of a qualitative and ethnomethodological research developed in a state public primary school, in Natal-RN (Brazil). It investigated the reception of literature reading by a 4 th grade teacher, who revealed not to like reading nor considered herself a literature reader. Theoretical foundations are based, mainly, on Coulon (1995; 1995a), Vigotsky (1989; 1991; 2003), Graves and Graves (1995), Smith (1991), Jauss (2002), Iser (1996; 1999) and Amarilha (2012; 2013). With sensitive listening we tried to provide scaffolding to the teacher in 30 reading sessions. Research proceedings were applied with flexibility aiming to attend the training process. As instrument of collecting data two semi-structured interviews were used with the teacher at the beginning and at the end of the research, and a field diary. It was observed that, in reading, the text-life relationship was established by the teacher with some naivety, which prevented her from experiencing the fictional as a symbolic, playful activity. However, there were changes and mediation was fundamental in this process

Keywords: Literature reading. Mediation. Teacher trainning.

\section{Introdução: os caminhos da jornada}

Ler. Ler por prazer. Ler para saborear, para crescer, para viajar. Ler para imaginar, para se perder, para se encontrar... Ler para conhecer. Conhecer para gostar. Gostar para querer ler mais...

Leitura e prazer misturam-se neste trabalho, centrado na perspectiva do leitor, no seu olhar, no seu saber, na sua emoção. Smith (1991, p. 212) afirma que, além de proporcionar muitas experiências de aprendizado, a leitura envolve as emoções. Também reconhece que a resposta emocional à 
leitura é tratada insuficientemente na maioria dos livros sobre alfabetização, "[...] embora esta seja a razão primária pela qual a maioria dos leitores lê, e provavelmente a razão primária pela qual a maioria dos não leitores não lê" Já Zilberman (1989, p. 40) assinala que Jauss tinha percebido essa lacuna e afirma que "[...] um setor permaneceu insuficientemente descrito: o da experiência do leitor que deveria ser, supõe-se, a matéria central de uma estética voltada para a análise da recepção". Eco (1999, p. 14), por sua vez, também faz referência à experiência e à emoção dos leitores, afirmando que eles"[...] podem ler de várias formas, e não existe lei que determine como devem ler, porque em geral utilizam o texto como um receptáculo de suas próprias paixões, as quais podem ser exteriores ao texto ou provocadas pelo próprio texto".

Consideramos, então, que este trabalho seria uma boa oportunidade para aprofundar na experiência, na resposta emocional, na razão primária dos leitores, nas suas paixões, e poder, assim, aportar novos dados que nos permitissem avançar mais um passo, na prazerosa tarefa de educar por meio da literatura. Partindo da ideia de que o "prazer também se ensina" (AMARILHA, 2012 , p. 921, a intenção desta investigação foi olhar do outro lado e ver o que acontece com o aprendizado desse prazer.

16 Foi, então, que nos encontramos com Virgínia (nome fictício), uma professora da quarta série de uma escola estadual de Natal-Rio Grande do Norte (Brasil), que reconheceu não gostar de ler nem se considerar leitora de literatura. Ela assumia essa falta de gosto como um problema e afirmava querer evitar que os seus alunos tivessem esse mesmo problema.

Assim sendo, e considerando que é preciso gostar de ler para promover o prazer pela leitura, perguntamo-nos: como proceder para que uma professora que não gosta de ler se torne leitora? Como será a sua recepção à leitura na experiência com diferentes textos literários?

Com essas perguntas, assumimos a formação leitora da professora por meio de uma pesquisa de caráter qualitativo e etnometodológico, estudando a sua recepção e a nossa atividade mediadora nesse processo. $\bigcirc$ intuito não era outro senão mediar para inaugurar, para incentivar, para possibilitar. Mediar para acompanhar, para construir e compartilhar.

Em busca de compreender o processo de formação leitora, a professora sujeito deste artigo forneceu alguns indicadores relevantes. Devido a modalidade de pesquisa realizada, estudo qualitativo etnometodológico, em 
que se aprofundou a relação pesquisadora e sujeito, a construção do discurso investigativo permanece contemporâneo, pois poucos são os estudos em que se apresenta de maneira singular a jornada em busca da formação em leitura de literatura de uma professora que vive uma contradição angustiante: não gosta de ler, mas não deseja dar a seus alunos esse testemunho. $\bigcirc$ presente artigo se baseia na dissertação de mestrado "Tenho um problema: não gosto de ler! A formação do leitor literário - construção compartilhada do prazer de ler" (ZUBERMAN, 2005), desenvolvida com uma professora de uma escola de ensino fundamental, da rede pública do Rio Grande do Norte, situada em Natal, Brasil.

Consideramos que a formação do/a professor/a leitor/a como mediador/a preferencial no processo de formação de novos leitores de leitura e de literatura é basilar. No entanto, a abordagem ao tema ainda é incipiente. Quase ausente nos cursos de graduação em Pedagogia, a área de literatura não tem como oferecer aos professores de educação infantil e das sereis inicias do ensino fundamental formação adequada. Assim sendo, refletir sobre esse problema continua atual como provocação a encaminhamentos de pesquisa, de organização curricular e de políticas públicas. Como se trata de pesquisa qualitativa, as reflexões, aqui desenvolvidas, apresentam teor de transferibilidade (MERRIAM; TISDELL, 2016) para muitas outras professoras e professores que vivenciam o mesmo dilema, precisam formar leitores, entretanto, não têm a oportunidade de serem acompanhadas em um processo sistemático e solidário de transformação que os habilitem para essa tarefa.

estudo focaliza a recepção da leitura de literatura por parte de uma professora que, no início da pesquisa, revelou não gostar de ler nem ser leitora de literatura e, reconheceu essa condição como um problema, que ela não deseja para os seus alunos. Neste artigo abordaremos, principalmente, o contrato ficcional e a relação texto-vida que essa professora estabeleceu na recepção aos textos literários a partir das sessões de leitura compartilhadas com a pesquisadora.

Nesse quadro de referência, tivemos como objetivo investigar a recepção da leitura de literatura por parte dessa professora que vivia um dilema profissional: seu fazer docente contradizia-se com sua própria identidade como (não) leitora. Eticamente, Virgínia sabia que não poderia negar a seus alunos o acesso à leitura, e à literatura, entretanto, ela própria se reconhecia como não leitora. Há implícito ao dilema da professora, o reconhecimento 
da importância da formação leitora para seus alunos e a evidência da sua precária relação com a leitura. A fragilidade que a angustia, no entanto, não a aliena de sua responsabilidade e esse é o ponto inicial de sua jornada formativa. $\bigcirc$ desdobramento desse objetivo, de caráter geral, converge para os seguintes objetivos específicos: refletir sobre a mediação que possibilita a essa professora tornar-se leitora; compreender quais são os aspectos que influem na relação entre o leitor em formação e a leitura de literatura; contribuir para que a professora possa aproveitar o seu acercamento à leitura literária para enriquecer-se como mediadora na formação de novos leitores.

Assim, o estudo teve como foco uma professora da quarta série do ensino fundamental, de 48 anos de idade, com 25 anos de serviço na rede pública do Rio Grande do Norte. Antes de 1979, ano em que concluiu o magistério, havia trabalhado como professora auxiliar em escolas particulares de educação infantil. No momento da pesquisa, cursava o terceiro ano de Pedagogia na Universidade Estadual do Vale Acaraú (UVA), em Natal, Rio Grande do Norte. Essa professora é Virgínia.

A pesquisa de campo foi realizada com flexibilidade, objetivando atender ao processo de formação leitora dessa professora. Para construir os dados, foram realizadas duas entrevistas com a professora, uma no início e outra no final do processo formativo compartilhado, que foram gravadas em áudio. A escolha de entrevistas semi-estruturadas, com a maioria das perguntas abertas, justifica-se pelo fato de esperar, por parte da docente, a elaboração de respostas pessoais baseadas em suas ideias e suas experiências enquanto leitora e professora, conforme orienta o modelo etnometodológico. Utilizou-se também, desde o primeiro dia de entrada em campo, notas de tudo o que acontecia na escola sob forma de um diário que incluía as datas, as descrições do trabalho realizado, reflexões, sensações e emoções da pesquisadora. Geralmente, o diário era escrito no mesmo dia da visita à escola para poder registrar a maior quantidade de informação possível, complementando as notas tomadas no campo. $\bigcirc$ diário resultou em instrumento indispensável para a pesquisa, pois foi utilizado tanto como espaço para registro de dados, quanto como espaço de análise e reflexão permanente. 


\section{Primeira etapa da jornada: sessões de Degustação Literária}

A degustação literária objetiva experimentar a leitura de literatura, para poder apreciá-la. Como é preciso conhecer para poder gostar, o intuito foi possibilitar o acercamento da professora a diferentes textos literários. Com esse propósito, foram realizadas 30 sessões de leitura, durante as quais foram lidos 5 relatos curtos, 17 contos, 3 poemas e 1 livro teórico de 167 páginas, composto de sessenta e sete fragmentos curtos organizados em quatro capítulos.

A leitura dos primeiros contos foi realizada em voz alta pela pesquisadora. Seguidamente, passamos a outro estágio no qual a professora acompanhava, com o texto em mãos, a leitura do livro teórico feita pela pesquisadora. Finalmente, na releitura de alguns dos contos, foi a professora quem realizou a leitura em voz alta.

Como todo conhecimento, a leitura se constrói socialmente, a partir da mediação de outros. Realizamos essa mediação por meio de uma ação semelhante a uma Tutoria, pois assumimos a formação sistemática da professora enquanto leitora de literatura e a acompanhamos durante nove meses, em encontros semanais. Embora tivesse uma sistematização teórico-metodológica planejada, esses encontros se caracterizaram pela flexibilidade e disposição da pesquisadora para se adaptar ao tempo da professora. Virgínia teve a seu dispor uma "professora" que cuidava apenas dela, modificava horários quando solicitado, se dedicava exclusivamente à sua formação leitora, relacionava-se empaticamente com ela abrindo espaços para que exprimisse sentimentos e preocupações pessoais, em verdadeiro exercício de escuta sensível (BARBIER, 1998). No entanto, ficou estabelecido um contrato implícito de responsabilidade, que Virgínia foi assumindo cada vez mais, comprometendo-se com o trabalho e valorizando a tarefa compartilhada, conseguindo, muitas vezes, afastar-se momentaneamente dos obstáculos da sua vida cotidiana.

\section{O marco teórico da jornada}

Em relação ao marco teórico do trabalho, tomamos como principal referente metodológico a Etnometodologia, pesquisa empírica dos métodos que os indivíduos utilizam para dar sentido e, ao mesmo tempo, realizar as suas ações de todos os dias, quer sejam triviais ou eruditas (COULON, 1995; 
1995a). De acordo com essa linha de pensamento, a realidade é constantemente criada pelos atores. Coulon enfatiza ser importante observar como os atores produzem o seu senso comum e tratam a informação nos seus contatos, e como utilizam a linguagem como um recurso.

Essa corrente da sociologia americana, decorrente dos trabalhos de Garfinkel nos anos 60, do século XX, tem múltiplas ligações com outras correntes de pesquisa em ciências sociais, dentre elas, a fenomenologia. Esta última estuda os fenômenos enquanto percebidos, resgatando a intencionalidade como visão de consciência e a produção de sentido. Essa produção de sentido, por parte da professora que começa a mergulhar no mundo da leitura de literatura é a que tentamos descobrir e compreender ao longo do trabalho.

Na convergência dessa postura epistemológica, a abordagem à relação do leitor com o texto, foco deste estudo, centra-se na perspectiva do leitor e considera fundamentais os conceitos da teoria da estética da recepção, formulada por Hans Robert Jauss e Wolfgang Iser da Escola de Constança, na Alemanha, no final dos anos de 1960. A estética da recepção aborda o processo de produção/recepção da obra literária partindo do leitor, mas sem desconhecer os aspectos estéticos e sociais implicados no processo da leitura 20 de literatura. Nessa teoria, a investigação muda de foco; passa do texto enquanto teoria imutável e auto-suficiente - para o leitor, como entidade real (ZILBERMAN, 1989).

À diferença de Jauss (2002; 2002a), que está interessado na maneira em que uma obra é ou deveria ser recebida, Iser (2002) se concentra no efeito que causa, na ponte que se estabelece entre um texto literário e o leitor. A interação dinâmica entre eles é descrita por Iser como o processo de leitura. Enquanto a teoria do efeito está ancorada no texto, a da recepção está ancorada nos juízos históricos dos leitores. Os seus olhares estão fixados em pontos diferentes, mas as duas teorias compartilham a ideia da participação ativa do leitor e da leitura literária como ato de comunicação.

Acreditamos, como afirma Smith (1991, p. 66) que "[...] a leitura é uma atividade social, apreendida (ou não) em um contexto social, em vez de intelectual". Então, considerando que a leitura se constrói socialmente, a partir da mediação de outras pessoas, adotamos como parte do marco teórico deste estudo a teoria socio-histórica de Vigotsky. Essa teoria considera o aprendizado como uma atividade social que influi no desenvolvimento do 
sujeito. A esse respeito, é relevante o conceito de Zona de Desenvolvimento Proximal - ZDP, definido por Vigotsky (1989) como a distância entre o nível de desenvolvimento real, determinado pela capacidade de resolver problemas independentemente, e o nível de desenvolvimento potencial, determinado pela solução de problemas sob a orientação de um adulto ou em colaboração com companheiros mais capazes. Vigotsky postula que a ZDP cria uma característica essencial do aprendizado, isto é, o aprendizado gera na criança uma série de processos evolutivos internos, produzidos somente em situações de interação e, em cooperação, com algum colega. Uma vez que foram internalizados, esses processos passam a formar parte dos ganhos evolutivos da criança. Assim, a criança será capaz de fazer sozinha amanhã aquilo que hoje faz com assistência. Seu nível de desenvolvimento real define funções que já amadureceram, produtos finais do seu desenvolvimento, enquanto que a ZDP define as funções que ainda não estão maduras, mas que estão em processo de maturação.

A metáfora do andaime no contexto de ensino-aprendizagem, que resulta em procedimentos de andaimagem, também se refere a uma situação de interação entre sujeitos, um com mais experiência que o outro no domínio em questão, em que o objetivo é que o sujeito menos experiente se aproprie gradualmente do saber por meio da colaboração do sujeito mais experiente, que atua como andaime. A formulação do termo andaimagem (scaffolding) foi feita por Woods, Bruner e Ross (1976). Eles o definiram como um processo que permite ao aprendiz resolver um problema, levando adiante uma tarefa que poderia estar além de seus esforços. Uma situação de andaime necessita de um suporte externo, audível e visível. Isso significa dizer que deve ser um dispositivo explícito para que o sujeito menos experiente tenha consciência da ajuda que está recebendo, do caráter intersubjetivo da sua atividade.

Graves e Graves (1995) propuseram uma experiência de leitura com andaime para ajudar os aprendizes a obter o máximo do texto. Eles afirmam que os leitores em formação precisam ter alguns desafios, mas que eles também precisam ter o necessário apoio ou andaime para enfrentá-los. E, assim, propõem suporte para o avanço cognitivo em leitura. Nessa experiência de leitura com andaime, Graves e Graves distinguem duas grandes fases: a de Planejamento e a de Implementação. Na fase de planejamento, o professor considera os estudantes, a seleção do texto e os propósitos para a leitura. A fase de implementação inclui atividades de pré-leitura, durante leitura e pós-leitura. Adotamos essa experiência de leitura por andaime como metodologia 
de trabalho na realização da leitura de literatura com a professora visto que apresenta coerência epistemológica com o processo formativo instaurado.

Analisaremos, a seguir, alguns aspectos que consideramos relevantes sobre a recepção ao texto de literatura por parte da professora Virgínia durante a formação realizada.

\section{A jornada em curso: "Será que acontece mesmo?" Ficção e realidade}

Virgínia se descrevia como uma pessoa que não gostava de ler, que não suportava a leitura. Nunca havia lido um livro inteiro sem pular páginas, sem fazer um grande esforço. Nunca havia vivenciado o prazer de ler.

A partir das primeiras leituras compartilhadas, nas quais a professora ouvia a pesquisadora ler, Virgínia começou a se surpreender. Ela não conseguia acreditar estar gostando do que ouvia. Começou a se animar, a exprimir sentimentos suscitados pelos textos, a estabelecer relações entre esses textos e a sua vida, a pedir ajuda para interpretá-los.

22 Para ilustrar o despertar do prazer de ler de Virgínia pela leitura de literatura, apresentamos um dos contos lidos na primeira sessão de leitura, $\bigcirc$ mundo, de Eduardo Galeano:

Um homem da aldeia de Neguá, no litoral da Colômbia, conseguiu subir aos céus.

Quando voltou, contou. Disse que tinha contemplado, lá do alto, a vida humana. E disse que somos um mar de fogueirinhas.

- O mundo é isso - revelou -. Um montão de gente, um mar de fogueirinhas.

Cada pessoa brilha com luz própria entre todas as outras. Não existem duas fogueiras iguais. Existem fogueiras grandes e fogueiras pequenas e fogueiras de todas as cores. Existe gente de fogo sereno, que nem percebe o vento, e gente de fogo louco, que enche $o$ ar de chispas. Alguns fogos, fogos bobos, não alumiam nem queimam; mas outros incendeiam a vida com tamanha vontade que é impossivel olhar para eles sem pestanejar, e quem chegar perto pega fogo (GALEANO, 1991, p. 13). 
Depois de ouvir o conto, Virgínia disse à pesquisadora que o tinha achado "MUITO LINDO" (ZUBERMAN, 2003). Tentou interpretar a história dizendo não saber se o que ela havia entendido se relacionava com o texto. Nós a encorajamos a falar e a confiar no que havia sentido e pensado enquanto ouvia o conto. Virgínia fez perguntas no sentido de entender como é que somos fogueirinhas. Ela disse que havia relacionado a história a pessoas que conhece e que também havia pensado muito em si: "[...] estou precisando brilhar, minha fogueira está um pouco apagada" (ZUBERMAN, 2003). Mostrou-se mobilizada, quase surpresa, por ter gostado do texto. Disse que o texto havia ficado nela e admitiu que isso era muito bom, mas estranhou porque "geralmente fica nada!" (ZUBERMAN, 2003).

Segundo Iser (1996), é necessário considerar o sentido não como algo a ser explicado, mas sim como um efeito a ser experimentado. Assim, a interpretação deixa de explicar uma obra e revelar o seu sentido para passar a revelar seus possíveis efeitos. No caso de Virgínia, podemos dizer que o estranhamento pelo envolvimento com o texto é indicador de que the causou um efeito novo, inaugural na sua jornada formativa.

Esses efeitos se relacionam à concretização da obra, produzida pelo leitor; quer dizer, com o seu polo estético, isto é, o leitor é tocado pela palavra do texto literário e essa palavra passa a participar do seu horizonte de expectativa. O outro polo da obra literária - o artístico - designa o texto criado pelo autor. "A obra é mais do que o texto, é só na concretização que a obra se realiza" (ISER, 1996, p. 50). E é nessa concretização que o leitor passa a ser protagonista, sujeito da leitura que faz. A sua atividade cognitiva e emotiva passa a ocupar um papel central, de modo tal que o que procuramos saber, no caso de Virgínia, é o que sucede com essa leitora quando dá vida aos textos ficcionais a partir da sua leitura, e não o que significa a obra que ela está lendo a priori. Não se trata de ignorar a produção textual tal qual se apresenta, mas de reconhecer a vitalidade que ganha quando o leitor assume seu status de protagonista da leitura.

Virgínia experimentou muitas sensações a partir daquela primeira leitura. Foi um texto lembrado por ela ao longo da pesquisa. O relato produziu na leitora variados efeitos significativos. Partiremos deles para realizar a nossa análise. No decorrer da leitura, a professora Virgínia procura interpretar o texto e pede ajuda para não cometer "erros". Essa atitude indica que ela ainda procura saber o que significa a obra, como se fossem tangíveis o certo e o 
errado na leitura de literatura, talvez como um dado da cultura escolar com que conviveu; reconhece os sentimentos que o texto the provoca, mas o concebe como uma mensagem acabada, da qual, ao contrário do afirmado por Iser, precisa explicar o sentido. Nessa busca de sentido, na qual Virgínia reconhece explicitamente que "a dificuldade de interpretação é grande!" (ZUBERMAN, 2003), ela não se percebe capaz de elaborá-lo. Para a professora é difícil compreender que os seres humanos podem ser fogueirinhas porque sua capacidade de metaforizar é precária e, portanto, encontra barreira em ir, sozinha, além da literalidade.

Segundo Machado (2002, p. 77-78), "[...] não se lê literalmente. Quem não tem intimidade com livros ignora isso. [...] A linguagem poética é simbólica, colorida, metafórica". A falta de contato com livros, o desconhecimento da linguagem poética e simbólica faz com que a professora não possa imaginar sozinha que as palavras escritas vão além da estrutura aparente do texto, concretizando-se na estrutura profunda, no plano da conotação, como assevera Smith (1991).

Com efeito, podemos afirmar que Virgínia demonstra pouca formação como leitora e como mediadora de futuros leitores. Na entrevista inicial, ela fez 24 referência a esse déficit na leitura tanto na sua formação profissional quanto na sua educação familiar. É interessante salientar que Virgínia foi alfabetizada e participa ativamente de uma sociedade letrada. Mas, considerando essa cultura como um processo de comunicação, de utilização da língua oral e da língua escrita para vários fins, podemos dizer que, na cultura letrada de Virgínia, muitas possibilidades de uso da escrita e da leitura não foram contempladas. A sua prática como educadora estava restrita ao uso funcional da língua, desconsiderando-se seu uso criativo, estético, imaginativo e fruidor. Evidencia-se que faltou a Virgínia uma mediação que colaborasse para que transitasse do uso referencial da língua para o conotativo, metafórico, essencial para se realizar como leitora de literatura. Essa professora estava excluída, marginal ao uso potencial da linguagem metafórica, num contexto que deveria incluíta.

Podemos relacionar a exclusão e a marginalidade nas práticas da linguagem com o que Foucambert (1998) define como iletramento:

iletramento, na verdade, designa pouca familiaridade com as razões do uso e com as redes da comunicação escrita - uma falta 
de busca da escrita enquanto elemento integrado aos temas de interesse e de preocupação. $\bigcirc$ iletramento define-se, assim, como a incultura da escrita - o desconhecimento tanto do que ela produz e transforma, como dos meios de ter acesso a ela e de participar. [...] A definição de iletramento remete sempre a um funcionamento social, tanto em suas práticas como em suas expectativas (FOUCAMBERT, 1998, p. 13).

Segundo esse autor, ser leitor implica em sentir domínio sobre o mundo assim que se compreende aquilo que o faz ser como é; significa ter consciência da sua condição e da transformação de si mesmo, dos outros e das coisas. Mas, a inserção numa sociedade desigual e segregativa impede muitas vezes a aquisição desse domínio e dessa consciência transformadora.

Longe daquela consciência transformadora, Virgínia se situa como uma receptora que está começando a conhecer um novo mundo a partir do seu conhecimento prévio, sentindo, muitas vezes, que ele não é suficiente para interpretar os textos lidos.

Vejamos um exemplo claro de literalidade na leitura de Virgínia. Em determinado encontro, lemos Da utilidade dos animais, uma crônica de Carlos Drummond de Andrade (2002) que satiriza uma professora transmitindo para seus alunos a utilidade dos animais. No final do texto, o personagem do aluno Ricardo responde para a professora que tinha entendido tudo direitinho: "[...] a gente deve amar, respeitar, pelar e comer os animais, e aproveitar bem o pelo, o couro e os ossos". Quando acabamos de ler a crônica, Virgínia se manifestou: "Está certo. Os animais têm muita utilidade" (ZUBERMAN, 2003). Tudo o que ela parecia ter entendido da leitura se referia ao respeito e carinho que temos de ter pelos animais, tendo perdido completamente o sentido irônico do texto. Relemos o final da crônica, mas Virgínia seguia compreendendo a ideia literal de amar, respeitar os animais e valorizar a utilidade deles. Tentamos convencê-la de que Ricardo havia entendido outra coisa e lemos, mais uma vez, a resposta final do aluno. Falamos da ironia, de outro sentido por trás do que a professora estava querendo transmitir para os seus alunos. Então, Virgínia exclamou: "Ah, sim, agora entendi!" (ZUBERMAN, 2003). Disse que isso acontece muito, que os alunos fazem questões que surpreendem os professores e que, muitas vezes, estes não esperam que as crianças façam críticas.

Aparece aqui um aspecto relevante da leitura de Virgínia, a necessidade de estabelecer relações entre os textos e a própria vida, tanto pessoal 
quanto profissional. Nesse último exemplo, a professora relaciona a resposta do personagem Ricardo com as intervenções dos seus alunos. Consideramos fundamental a atitude de relacionar o texto com a própria vida, de maneira a atribuir sentido ao que se lê. Segundo Smith (1991), a leitura não pode ser separada das finalidades dos leitores e de suas consequências sobre eles. A linguagem escrita faz sentido quando os leitores podem relacioná-la àquilo que sabem; e a leitura se torna interessante e relevante para eles quando pode ser relacionada àquilo que desejam saber.

Sabemos que, nessa atividade, o leitor é ativo. Realiza a atribuição de sentido a partir do que já conhece, do que já faz parte da sua experiência, das suas representações acerca da realidade, da cultura em que está inserido. Ao relacionar o que já sabe com o que deseja aprender, o sujeito realiza uma construção pessoal e subjetiva de algo que existe objetivamente. Ao elaborar essa construção pessoal, o leitor se implica no processo de aprendizado e pode, então, atribuir significado àquilo que está aprendendo.

Dessa forma, é indubitável o fato positivo de se estabelecer a relação texto-vida, de se identificar com os personagens das histórias lidas. Mas, não podemos esquecer a necessidade de nos distanciarmos para compre26 endermos a "realidade" dos personagens, como distinta da nossa. Quando Virgínia (2004) relaciona a resposta do personagem Ricardo às perguntas inesperadas dos seus alunos, não procura aprofundar os motivos que geraram aquela resposta, isto é, a atitude da professora que pretende transmitir aos alunos a utilidade dos animais revelando o aproveitamento predatório que o ser humano faz dessas criaturas, contradizendo-se com a abertura da aula em que afirmou: "É preciso querer bem a eles [...] Eles têm direito à vida, como nós" (ZUBERMAN, 2003). Ou seja, ao mesmo tempo em que afirma que devemos respeitar os animais, a professora personagem prossegue mostrando os diferentes usos que deles se pode fazer como alimento, agasalho, ornamentos. Virgínia não percebe a ironia presente na história. É importante ressaltar que a identificação precisa ser acompanhada da abstração, da possibilidade de participar do jogo simbólico favorecido pela leitura de literatura, ou seja, Virgínia pode sim, observar que alunos fazem perguntas inesperadas, são críticos, o que surpreende os professores, entretanto, esse tópico é periférico em relação a toda a argumentação desenvolvida pela crônica de Drummond.

Para interagir com a reflexão irônica do texto, o leitor precisa engajar se na proposta de diálogo ali apresentada e entender que está em um processo 
de visão em perspectiva, em distanciamento, em que o que é dito esconde o não dito. A identificação de Virgínia com a professora da crônica, enquanto aquela que deve ministrar uma aula com um discurso linear, coerente, atende a uma concepção de dar aula, mas falha em compreender de maneira crítica o seu próprio discurso, o que o personagem do aluno faz com propriedade, o que desorienta a mediação da professora. Foi esse detalhe que chamou a atenção de Virgínia porque, provavelmente, aí esteja um indício de sua vulnerabilidade como leitora e como mediadora. Como ela tem dificuldade em ler de maneira abstrata, e ao mesmo tempo, conforme já demonstrado por Smith, o leitor lê com o que já conhece, o que Virgínia experimenta como leitora da crônica começa pela identificação com a personagem da professora, com a situação da sala de aula. O discurso de Virgínia mostra a relevância da identificação como um primeiro acercamento ao texto. Como afirma Amarilha, a identificação com os personagens de uma narrativa

[...] dá ao leitor ou ouvinte a possibilidade de suspender, transitoriamente, a relação com o cotidiano e viver outras vidas. Quando [...] o leitor vive os dramas pela história, [...] é introduzid[o] no jogo simbólico de ser personagem, enquanto não deixa de ser leitor. Esses dois níveis de acesso à abstração simbólica são, pedagogicamente, relevantes para o indivíduo que quanto mais avança para o crescimento mais envolvido fica em uma sociedade estruturada em códigos, portanto, símbolos (AMARILHA, 2012, p. 55).

Para Virgínia não era fácil viver essas outras vidas, ela primeiro vive um espelhamento direto com a personagem da professora e por isso precisa de andaimagem para poder percorrer a zona de desenvolvimento proximal e chegar à abstração simbólica. Virgínia estava, nesse primeiro momento, usando a literatura como um meio para "se analisar" e "se compreender". Entretanto, esse não era um processo linear. Podemos observar que o encontro com a literatura causava instabilidade, produzia efeitos em suas percepções, como é indicadora uma pergunta muito recorrente nas sessões de leitura: "Será que acontece mesmo?" (ZUBERMAN, 2003). Assim como na história das fogueirinhas, Virgínia precisou de andaimes concretos para compreender a linguagem metafórica. Nas demais histórias, precisou estabelecer relações com anedotas reais da sua vida para thes atribuir sentido, em um movimento ainda precário de compreender a ficção como ficção, como um contrato com um jogo lúdico, com o simbólico. 
Podemos exemplificar o dito anteriormente com a sessão de leitura de medo e o relógio (ANDRADE, 2002). Trata-se da história de uma mulher que não gostava de ir à cidade por ter medo de ser assaltada. Certo dia, teve de sair para fazer um pagamento porque o marido estava doente. Caminhava com muito medo pelas ruas e, de repente, sentiu que um homem se encostava ao seu braço, puxando-o. Começou a gritar e a pedir que alguém segurasse o ladrão que tinha roubado o seu relógio. $\bigcirc$ homem colocou rapidamente o relógio na mão dela e fugiu da multidão. Quando a mulher chegou em casa descobriu que tinha esquecido o seu relógio na mesinha-de-cabeceira e que o relógio restituído não lhe pertencia.

Virgínia achou a história muito interessante. Disse que a personagem "[... nem se tocou que não estava com o relógio". Tudo aconteceu "[...] porque ela já saiu assustada, com medo. Muito interessante. Será que acontece mesmo? Como o medo faz muita coisa!". Depois, a professora relatou uma anedota que tinha acontecido com ela no dia anterior: tinha atravessado a avenida com o sinal fechado (acreditando que estivesse aberto para ela) e havia muitos carros transitando em alta velocidade. Quando ela se deu conta, começou a correr muito. Virgínia disse acreditar que o medo havia salvado a 28 sua vida. Manifestou ter gostado muito do texto e ter achado interessante o fato de escutar histórias do dia a dia, da vida mesma (ZUBERMAN, 2003).

Virgínia transfere a sua realidade para o mundo simbólico da ficção de maneira integral. A falta de experiência com o mundo ficcional faz com que Virgínia não consiga diferenciá-lo claramente do seu mundo real. Como afirma Amarilha (2012, p. 9), "[...] representar implica em ter consciência de ser 'eu' e experimentar-se como 'outro' [...]". Nesse sentido, Virgínia só consegue experimentar-se como 'eu' e relacionar suas experiências com as dos 'outros'. Outros que, embora ela chame de personagens, não parece distingui-los das pessoas do seu mundo. Não experimenta a irrealização descrita por Iser (1999), no sentido de estar preocupada com algo que a separa da sua realidade dada, pois não se concebe separada dessa realidade.

Aparece aqui uma dificuldade em aceitar o acordo ficcional, em fingir que realmente aconteceram os fatos narrados nos livros. Muitos autores (ECO, 1999; ISER, 1996; MACHADO, 2002) citam a expressão utilizada pelo crítico inglês Coleridge (2004) para se referir a esse acordo que passa a unir autor e leitor, qual seja, a "suspensão da descrença". Assim, o leitor experiente leva a sério o que a ficção the oferece e deixa-se cativar por ela; sai do seu mundo, 
se abstrai dele, viaja pelos mundos ficcionais e acredita, durante a viagem, que os animais falam, que os marcianos são verdes, que as bruxas voam de vassoura e que se pode chegar perto do sol sem se queimar... "Justamente por não ser idêntica ao mundo, nem ao receptor, a ficção possui capacidade comunicativa" (ISER, 1999, p. 125).

Virgínia precisa, ainda, se perguntar se os fatos relatados nos textos podem acontecer, precisa vivenciar a ficção como factual, estabelecendo relações diretas com a sua vida cotidiana.

\section{Pontos de ancoragem da jornada}

Na recepção de Vírginia ao contato com a literatura, dois aspectos devem ser considerados. De um lado, Virgínia conseguiu se engajar com as histórias lidas, identificar-se com alguns personagens, relacionar os relatos com a própria vida e admitir que a leitura estava começando a the gerar prazer. Isso tudo implica em avanço significativo na sua relação com a leitura de literatura. A partir da descoberta de que a leitura de literatura pode ter muito a the dizer sobre a vida, a partir do prazer de sentir que algumas histórias podem "ficar nela" e mobilizar os seus sentimentos é que Virgínia começou a dar sentido à leitura, a ressignificar essa atividade e a deixar entrar na sua vida de uma maneira diferente do que tinha sido até antes da pesquisa. Encontrar no relato sobre as fogueirinhas a possibilidade de começar - através da mediação - a simbolizar e metaforizar a sua realidade é um passo muito significativo nesse longo caminho de formação leitora.

De outro lado, no entanto, essa relação entre os textos e a sua vida era estabelecida ainda com certa ingenuidade, o que impedia Virgínia de vivenciar o ficcional como uma atividade lúdica. Se ela não conseguir suspender a descrença e continuar questionando se os fatos lidos podem realmente acontecer, suas viagens literárias serão sempre limitadas. Virgínia necessita estabelecer um contato mais profícuo e regular com os textos de ficção, de modo a avançar no caminho iniciado, no sentido de conseguir se distanciar de si e adquirir a autonomia e consciência transformadora que the permitirão ir e voltar da realidade para a ficção enriquecendo-se, sem confundi-las.

Outra reflexão relevante da pesquisa é que a passagem da formação leitora inicial para a ação pedagógica adequada é complexa; implica em 
inserção na cultura da leitura, em tempo e qualificação constante da professora, tanto como leitora, quanto como mediadora. De um lado, o contexto institucional em que a professora trabalha não promove a paixão pelo conhecimento. De outro lado, embora Virgínia reconheça a importância que the proporcionou o Curso de Pedagogia, também não the parece ter gerado paixão.

A tutoria realizada com Virgínia propicia um olhar focal e cotidiano nas condições de preparo e de estrutura que afetam essa docente de uma escola pública brasileira, permitindo, também, vislumbrar possibilidades concretas de começar a melhorar aquelas condições. Assim mesmo, o trabalho realizado deixa contradições mapeadas e perguntas abertas. Não sabemos como continuará a história leitora da professora; não sabemos se ela terá conseguido realizar aulas de leitura com seus alunos, uma vez por semana, tal como ela havia pensado fazer, depois de terminar a nossa pesquisa; não sabemos se Virgínia seguirá procurando livros, encontrando histórias que fiquem nela e escolhendo textos para ler e compartilhar na sala de aula com seus alunos, por prazer... Mas, esta pesquisa deixa, também, a certeza de que é possível mudar as práticas leitoras por meio de um intensivo trabalho formativo compartilhado.

\section{Referências}

AMARILHA, Marly. Estão mortas as fadas? Literatura infantil e prática pedagógica. 9. ed. Rio de Janeiro: Vozes, 2012.

Alice que não foi ao país das maravilhas: educar para ler ficção na escola. São Paulo: Livraria da Física, 2013.

ANDRADE, Carlos Drummond de. As palavras que ninguém diz: crônica. 6. ed. Rio de Janeiro: Record, 2002.

BARBIER, René. A escuta sensível na abordagem transversal. In: BARBOSA, Joaquim (Coord.). Multirreferencialidade nas ciências e na educação. São Carlos: Editora da UFSCar, 1998.

COLERIDGE, Samuel Taylor. Biographia literaria. Release Date: July. 2004. Last Update 26 jan. 2013. Disponível em: http://www.gutenberg.org/ebooks/6081. Acesso em: 13 abr. 2017. [Ebook]. 
COULON, Alan. Etnometodologia. Tradução Ephraim Ferreira Alves. Rio de Janeiro: Vozes, 1995.

Etnometodologia e educação. Tradução Guilherme João de Freitas Teixeira. Rio de Janeiro: Vozes, 1995a.

ECO, Umberto. Seis passeios pelos bosques da ficção. 3. ed. Tradução Hildegard Feist. São Paulo: Companhia das Letras, 1999.

FOUCAMBERT, Jean. A criança, o professor e a leitura. Tradução Marleine Cohen e Carlos Mendes Rosa. Porto Alegre: Artes Médicas, 1998.

GALEANO, Eduardo. O livro dos abraços. 2. ed. Tradução Eric Nepomuceno. Porto Alegre: L\&PM, 1991.

GRAVES, Michael; GRAVES, Bonnie. The scaffolded reading experience: a flexible framework for helping students get the most out of text. Reading, Oxford, v. 29, n. 1, p. 29-34, apr. 1995.

ISER, Wofgang. O ato da leitura: uma teoria do efeito estético. Tradução Johannes Kretschmer. São Paulo: Editora 34, 1996.

O ato da leitura: uma teoria do efeito estético. 2. ed. Tradução Johannes Kretschmer.

São Paulo: Editora 34, 1999.

ISER, Wofgang. A interação do texto com o leitor. In: COSTA LIMA, Luiz. A literatura e o leitor. Textos da estética da recepção. 2. ed. Rio de Janeiro: Paz e Terra, 2002.

JAUSS, Hauss. Robert. A estética da recepção: colocações gerais. In: COSTA LIMA, Luiz. A literatura e o leitor. Textos da estética da recepção. 2. ed. rev. e ampl. Rio de Janeiro: Paz e Terra, 2002.

prazer estético e as experiências fundamentais da poiesis, aisthesis e katharsis. In: COSTA LIMA, Luiz. A literatura e o leitor. Textos da estética da recepção. 2. ed. Rio de Janeiro: Paz e Terra, 2002a.

MACHADO, Ana Maria. Como e por que ler os clássicos universais desde cedo. Rio de Janeiro: Objetiva, 2002.

MERRIAM, Sharan B.; TISDELL, Elizabeth J. Qualitative Research: a guide to design and implementation. 4. ed. San Francisco, CA: Josey Bass, 2016.

SMITH, Frank. Compreendendo a leitura: uma análise da leitura e do aprender a ler. 3. ed. Porto Alegre: Artes Médicas, 1991. 
VIGOTSKY, Lev Semenovich. A formação social da mente. 3. ed. Tradução José Cipolla Neto; Luis Silveira Menna Barreto e Solange Castro Afeche. São Paulo: Martins Fontes, 1989.

Pensamento e linguagem. 3. ed. Tradução Jeferson Luiz Camargo. São Paulo: Martins Fontes, 1991.

Psicologia pedagógica. Tradução: Claudia Schilling. Porto Alegre: Artmed, 2003.

WOODS, David; BRUNER, Jerome; ROSS, Gail. The role of Tutoring in Problem-Solving. Journal of Child Psychology and Psychiatry, v. 17, n. 2, p. 89-100, 1976.

ZILBERMAN, Regina. Estética da recepção e história da literatura. São Paulo: Editora Ática, 1989.

ZUBERMAN, Flavia. Tenho um problema: não gosto de ler! A formação do leitor literário - construção compartilhada do prazer de ler. 2005. 235f. Dissertação Mestrado em Educação) - Programa de Pós-Graduação em Educação, Universidade Federal do Rio Grande do Norte, Natal, 2005.

ZUBERMAN, Flavia. Diário de campo. Natal (Rio Grande do Norte, Brasil), 6 out. 2003.

32 ZUBERMAN, Flavia. Diário de campo. Natal (Rio Grande do Norte, Brasil), 13 out. 2003 a.

ZUBERMAN, Flavia. Diário de campo. Natal (Rio Grande do Norte, Brasil), 20 out. 2003b.

ZUBERMAN, Flavia. Diário de campo. Natal (Rio Grande do Norte, Brasil), 27 out. 2003c.

Ms. Flavia Zuberman

Ministério de Educação | Argentina

Grupo de pesquisa Ensino e Linguagem (CNPq/UFRN)

E-mail | flazuberman@hotmail.com

Profa. Dra. Marly Amarilha

Universidade Federal do Rio Grande do Norte

Departamento de Fundamentos e Políticas da Educação

Programa de Pós-Graduação em Educação

Grupo de Pesquisa Ensino e Linguagem (CNPq/UFRN) 
E-mail | marlyamarilha@yahoo.com.br

Recebido 31 out. 2017

Aceito 15 nov. 2017 